\title{
Seismic Velocity Monitoring Using Ambient Noise Observed by DONET Seismometers in the Nankai Trough, Japan
}

\author{
Toshinori KIMURA ${ }^{1}$, Hitoshi MIKADA ${ }^{2}$, Eiichiro ARAKI ${ }^{1}$ and Yuya MACHIDA ${ }^{1}$ \\ ${ }^{1}$ Japan Agency for Marine-earth Science and Technology (JAMSTEC) \\ ${ }^{2}$ Dept. of Civil and Earth Res. Eng., Kyoto University
}

\begin{abstract}
Subduction zones, where a tectonic plate subducting beneath the other plate, megathrust or interplate earthquakes could be generated repeatedly. Because of the nature of interplate earthquakes, the process of plate subduction governs the distribution, mechanics, and style of slip along the interplate fault. At the Nankai Trough subduction zone, located beneath the Pacific Ocean off the southeast coast of Japan, we have installed a seismic observation system, named DONET (Dense Oceanfloor Network system for Earthquake and Tsunamis), which is composed of twenty seafloor broadband seismometers and a borehole vertical seismic array to monitor the seismic activity and the process of earthquake generation including the stress accumulation. To elucidate earthquake generation and preparation process, it is necessary to investigate how the stress could be accumulated not only in deeper part but also in the shallow sediments, what the role of interstitial fluid could be in the stress accumulation processes, etc. There are some conventional methods to measure these physical properties, such as borehole strainmeter, borehole breakouts or borehole dynamic tests. However, these methods have some difficulties from the viewpoints of technical and/or cost. For example, borehole breakouts and dynamic tests can be conducted only while drilling and/or immediately after that. Therefore we need to have some other methods to see the state and variation of the stress in the subseafloor. In this study, we applied seismic interferometry technique to ambient noise records observed by horizontal components of DONET KMD13 seafloor seismometer to obtain time dependent S-wave velocity and its anisotropy as a proxy of stress state below the DONET observatory. We first calculated cross-diploe 4-C pseudo shot records from every 1 hour ambient noise records observed by horizontal components of the DONET seismometer for three years. In obtained 4-C shot records, clear phases, which should be caused by S-wave anisotropy, are visible. Alford rotation method was then applied to the 4-C shot records to obtain S-wave anisotropy parameters, directions of fast $\mathrm{S}$-wave and time lag between fast and slow S-wave velocities below the DONET observatory. We expected that our method could be a simple tool to monitor stress state in the Nankai Trough seismogenic zone.
\end{abstract}

\section{INTRODUCTION}

In the Nankai Trough subduction zone, Japan, Philippine-sea plate is subducting beneath the Eurasian plate with the rate of approximately 4.5 $\mathrm{cm} /$ year, and M 8.0 class huge mega-thrust earthquake occurred repeatedly with interval of 100 to 150 years (Seno, 1993). In this area, we are operating cabled seismic observation system, named DONET (Dense Ocenfloor Network systems for Earthquake and Tsunamis), which includes twenty three-components seismometers deployed on the seafloor (Kaneda et al., 2015; Kawaguchi et al., 2015) (Fig. 1). These seismometers were mainly distributed for passively monitoring natural earthquake related phenomena, e. g. regional microearthquakes, VLF (Very Low Frequency) events, seismic microtremors, etc. in the seismogenic zone.

For elucidating preparation and generation process of mega-thrust earthquake, which occurs repeatedly in subduction zones, it is important to observe and monitor the stress state, which is a key parameter governing its fault dynamics in the vicinity of seismogenic fault. In-situ stress analysis such as borehole breakout analysis may provide the orientation and the order of differential stress around the borehole, but it is still challenging to drill seismogenic fault, and is even more difficult to monitor temporal change of stress state, especially in wide area. Therefore, we have to consider another method to estimate stress state. In this study, we performed passive seismic data processing to obtain seismic anisotropy using dataset acquired by three-component seismometers installed in the 
DONET observatories. Seismic anisotropy can be a proxy of stress state, and furthermore, its temporal change is expected to identify change of stress around the seismogenic fault.

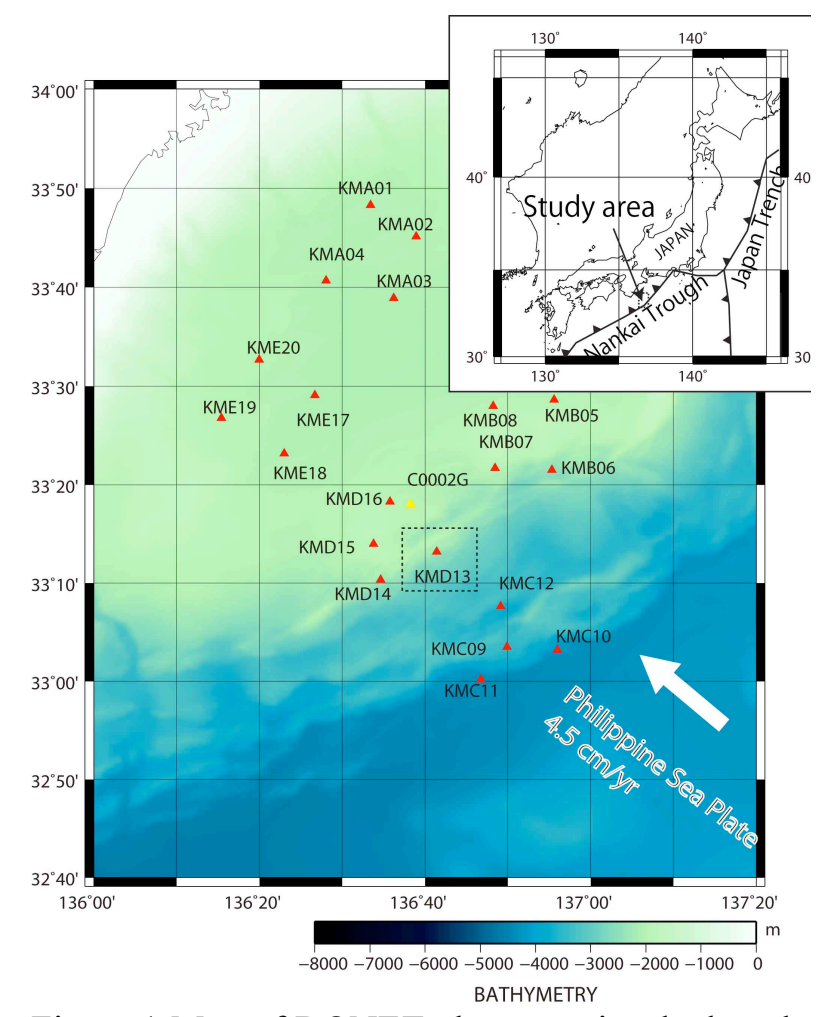

Figure.1 Map of DONET observatories deployed in the Nankai Trough. Triangles show the observatories. Red triangles indicate locations of DONET seafloor observatories, and .yellow triangle shows location of the IODP borehole subseafloor observatory (Kimura et al., 2013). KMD13 observatory is indicated by dashed rectangle.

\section{METHOD}

Seismic interferometry can retrieve the impulse response by the cross-correlation of seismic records simultaneously acquired by the two seismometers (Schuster, et al., 2004; Wapenaar and Fokkema, 2006). In this study, we applied seismic interferometry to ambient noise records acquired by horizontal components of each seismometer. Because the horizontal components are dominated by $\mathrm{S}$-wave energy, we expected that obtained auto-correlation function (ACF) and cross-correlation function (CCF) would provide us the knowledge of S-wave velocity and anisotropy beneath seafloor. In obtained ambient noise records, predominant peak of microseisms ranges from 0.15 $\mathrm{Hz}$ to $2 \mathrm{~Hz}$ is clearly visible. Microseisms are major ambient noise which is generated by ocean swell loading the seafloor (Longuet-Higgins, 1950) and propagate in the seafloor as Stoneley wave (Kedar et al., 2008). In this study, we used band-pass filter with pass band of $2-10 \mathrm{~Hz}$ for the following processing.

Then we obtained zero offset 4-C ACF and CCFs calculated from horizontal components of each seismometer. In the $\mathrm{x}-\mathrm{y}$ plane of the Cartesian coordinates, the 4-C records can be written as the following:

$$
\mathrm{V}=\left(\begin{array}{ll}
v_{11} & v_{12} \\
v_{21} & v_{22}
\end{array}\right),
$$

where vij represents virtual shot records with $i$-direction source and $j$-direction receiver component. For example, $v_{12}$ represents the virtual shot record with $\mathrm{x}$-direction source and $\mathrm{y}$-direction receiver obtained from cross-correlation between $\mathrm{x}$ and y-component of the seismometer. We obtained $\mathrm{ACF}$ and CCFs calculated from each 1 hour dataset of continuous ambient noise records.

To estimate anisotropy information from the obtained 4-C ACF and CCFs, we applied Alford rotation to the 4-C dataset. The Alford rotation is a widely used method to determine first and slow directions of S-wave anisotropy. The rotation can be performed as following equation (Alford, 1986).

$U=\left(\begin{array}{ll}\left(\cos ^{2} \theta v_{11}+\sin ^{2} \theta v_{22}\right. & \left(\cos ^{2} \theta v_{12}-\sin ^{2} \theta v_{21}\right. \\ \left.+.5 \sin 2 \theta\left(v_{21}+v_{12}\right)\right) & \left.+.5 \sin 2 \theta\left(v_{22}-v_{11}\right)\right) \\ & \\ \left(\cos ^{2} \theta v_{21}-\sin ^{2} \theta v_{12}\right. & \left(\cos ^{2} \theta v_{22}+\sin ^{2} \theta v_{12}\right. \\ \left.+.5 \sin 2 \theta\left(v_{22}-v_{11}\right)\right) & \left.-.5 \sin 2 \theta\left(v_{21}-v_{12}\right)\right)\end{array}\right)$

We can obtain counter clockwise rotated 4-C data from equation (2). If the rotated angle $\theta$ is agreed with the direction of the S-wave anisotropy, the off-diagonal element of matrix (2) can be minimized. In practical, we calculated power of off-diagonal elements of the rotated 4-C matrix with the rotated angle changing and find the optimum value of the angle using time windows that include target reflection wave. The amplitude of the S-wave anisotropy can be calculated the time difference of the target reflection wave between $v_{11}$ and $v_{22}$.

\section{DATA PROCESSING}

We applied seismic interferometry method and Alford rotation to continuous ambient noise records observed by horizontal components of DONET seismometers. KMD13 observatory was first 


\section{Hourly 4-C records calculated from DONET KMD13 ambient noise records}

(from Feb. 2013 to Feb. 2016)
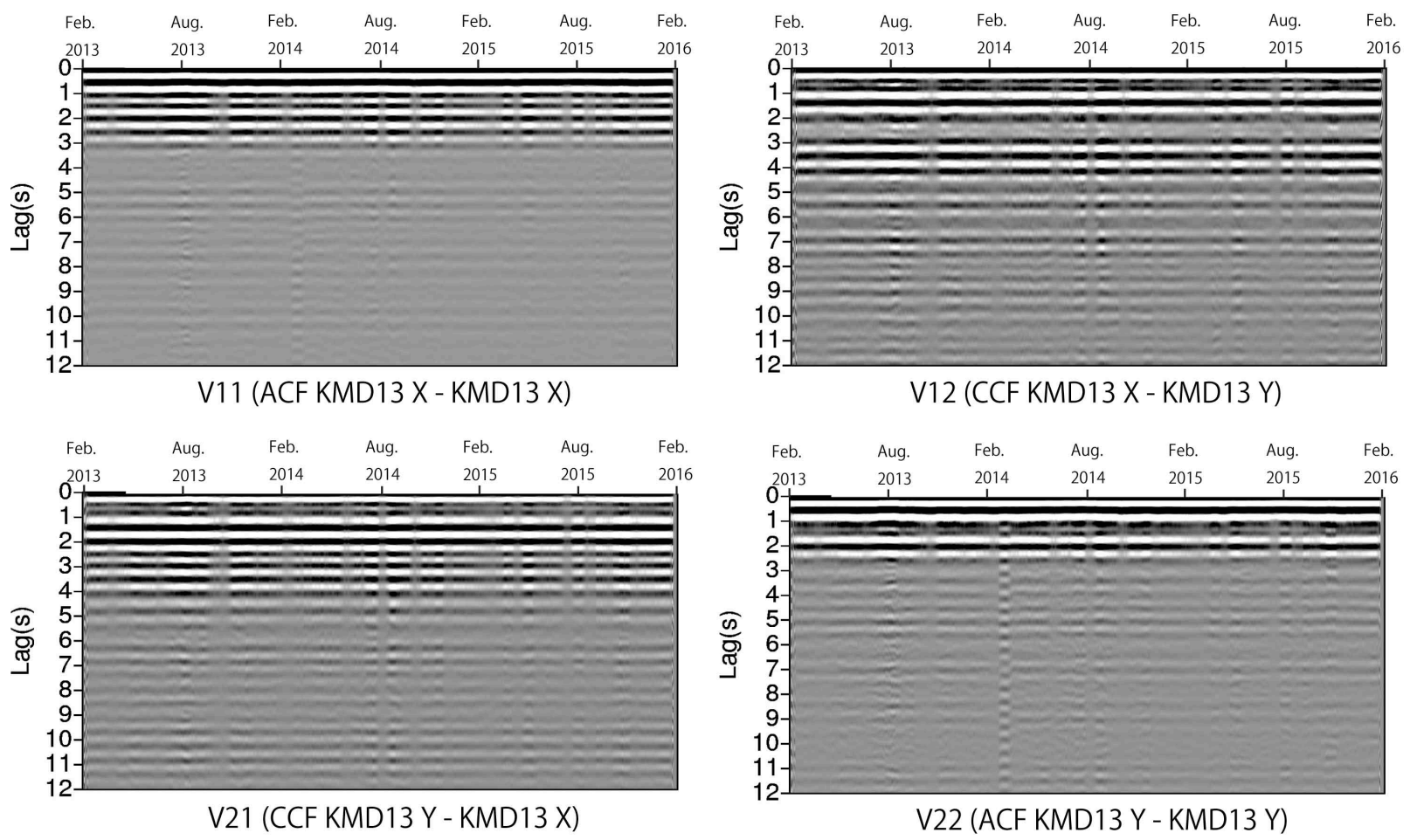

Figure 2 Example of the hourly 4-C data calculated from ambient noise records acquired by DONET KMD13 seismometer using continuous records from February 2013 to February 2016. Hourly 4-C data were obtained from each one hour dataset, and were averaged with window length of 24 hour (1 day).

chosen as a dataset for this study. Fig. 2 shows 4-C $\mathrm{ACF}$ and CCFs, which were calculated from ambient noise records obtained by DONET KMD13 seismometer form $1^{\text {st }} \mathrm{Feb} .2013$ to $30^{\text {th }}$ Jan. 2016. In hourly $4-\mathrm{C}$ records, coherent events are visible mainly in 1.0 to $5.0 \mathrm{~s}$. A simple travel time calculation using the simple layered velocity model confirmed that these events should include S-wave, which are reflected from the seafloor and propagate in the shallow sediment layer.

We then applied Alford rotation to the obtained 4-C data to obtain S-wave anisotropy, azimuth and amplitude for each observatory. Simple layered models were assumed for the Alford rotation with

Table 1 Velocity parameters for KMD13 observatory.

\begin{tabular}{ccc}
\hline Layen\# & Vs m s $(\mathrm{m} / \mathrm{s})$ & Twt $(\mathrm{s})$ \\
\hline \hline 1 & 700 & 2.0 \\
2 & 1800 & 4.5 \\
3 & 1500 & 6.5 \\
\hline
\end{tabular}

layer stripping algorithm (Thomsen et al., 1999). In this study, S-wave velocity models were calculated from P-wave velocity model (Kamei et al., 2012) and Castagna equations (Castagna et al., 1985). Table 1 describes velocity parameters used for the KMD13 observatory.

Fig. 3 shows time variation of S-wave anisotropy parameters in layer 2. The fast S-wave directions are almost parallel to subducting direction. Amplitudes of S-wave anisotropy are $4.5 \%$. Standard deviations of directions and amplitudes, which are calculated from 10 days dataset, are approximately less than 0.5 deg., and $0.3 \%$, respectively. These values imply resolutions of this approach used as a $\mathrm{S}$-wave anisotropy monitoring tool. For layers 1 and 3, amplitude of S-wave anisotropy are quite small, less than $0.5 \%$, and therefore directions of fast S-wave cannot be determined. We now plans to perform a robust statistical method to improve signal to noise ratio.

\section{CONCLUSION}




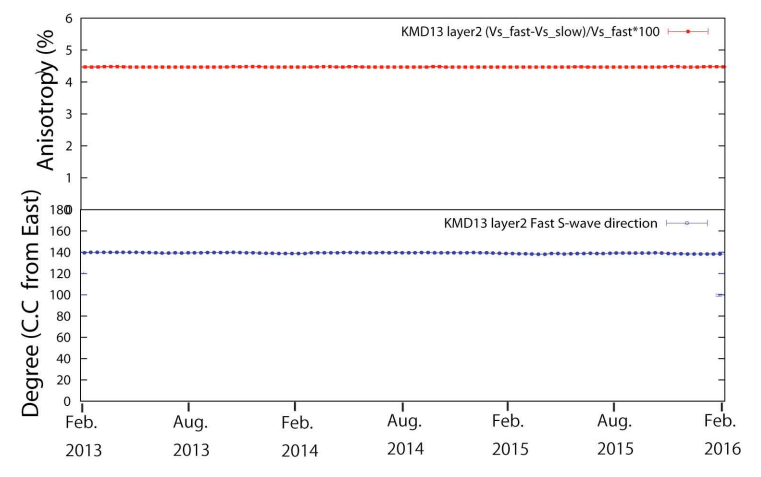

Figure 3 Time variation of S-wave amplitude (top) and fast S-wave direction (bottom) in layer 2.

We applied seismic interferometry method and Alford rotation to ambient noise records observed by DONET seafloor seismometer deployed in the Nankai Trough, Japan. Then depth-dependent $\mathrm{S}$-wave anisotropy with time variation was obtained below the DONET KMD13 observatory. Although further analysis and discussions, such as quantitative discussion of the relationship between S-wave anisotropy and stress, are still needed, we expected that our method can be a simple tool to monitor stress state in the Nankai Trough seismogenic zone.

\section{REFERENCES}

1) Seno, T., Stein, S. and Gripp, E., A. [1993] A model for the motion of the Philippine Sea plate consistent with NUVEL-1 and geological data. Journal of Geophysical Research, 89, 17941-17948.

2) Kaneda, Y., Kawaguchi, K., Araki, E., Matsumoto, H., Nakamura, T. et al., 2015, Development and application of an advanced ocean floor network system for megathrust earthquakes and tsunamis, Seafloor Observatories, P. Favali et al., Springer Praxis Books, doi 10.1007/978-3-642-11374-1_25, pp. 643-662, 2015.

3) Kawaguchi, K., Kaneko, S., Nishida, T., and Komine, T., Construction of the DONET real-time seafloor observatory for earthquakes and tsunami monitoring, Seafloor Observatories, P. Favali et al., Springer Praxis Books, doi 10.1007/978-3-642-11374-1_10, pp. 211-228, 2015

4) Kimura, T., Araki, E., Takayama, H, Kitada, K., Kinoshita, M., Namba, Y., and Kyo, M., 2013, Development and Performance Tests of a Sensor Suite for a Long-Term Borehole Monitoring System in Seafloor Settings in the Nankai Trough,
Japan, IEEE Journal of Oceanic Engineering, 38, pp. 383-395, 2013.

5) Schuster, G. T., Yu, J., Sheng, J., and Rickett, J., 2004, Interferometric/daylight seismic imaging, Geophys. J. Int., 157, 838-852.

6) Wapenaar, K., and Fokkema, J., 2006, Green's function representations for seismic interferometry, Geophysics, 71, SI33-SI46.

7) Longuet-Higgins, M. S., 1950, A theory of the origin of microseisms, Philosophical Transactions of the Royal Society A, 243, 1-35.

8) Kedar, S., Longuet-Higgins, M. S., Webb, F., Graham, N., Clayton, R., and Jones, C., 2008, The origin of deep ocean microseisms in the North Atlantic Ocean, Proceedings of the Royal Society A, 464, 777-793.

9) Alford, R. M., 1986, Shear data in the presence of azimuthal anisotropy: Dilley, Texas, 56th Annual International Meeting, SEG, Expanded Abstracts, 86, 81-82.

10) Thomsen, L., Tsvankin, I., and Mueller, M. C., 1999, Coarse-layer stripping of vertically variable azimuthal anisotropy from shear-wave data, Geophysics, 64, 1126-1138.

11) Kamei, R., Pratt, R. G., and Tsuji, T., 2012, Waveform Tomography Imaging of a Megasplay Fault System in the Seismogenic Nankai Subduction Zone, Earth and Planetary Science Letters, 317-318, 343-353.

12) Castagna, J. P., Batzle, M. L., and Eastwood, R. L., 1985, Relationships between compressional-wave and shear-wave velocities in clastic silicate rocks, Geophysics, 50, 571-581. 